\title{
Effects of Lactococcus lactis subsp. lactis I2 with $\beta$-Glucooligosaccharides on Growth, Innate Immunity and Streptococcosis Resistance in Olive Flounder (Paralichthys olivaceus)
}

\author{
Md Tawheed Hasan ${ }^{1 \dagger}$, Won Je Jang ${ }^{1 \dagger}$, Jin Yeong Tak ${ }^{1}$, Bong-Joo Lee ${ }^{2}$, Kang Woong Kim², Sang Woo Hur ${ }^{2}$, \\ Hyon-Sob Han², Bo-Seong Kim³ ${ }^{3}$ Min-Do Huh ${ }^{3}$, Shin-Kwon Kim ${ }^{4}$, and In-Soo Kong ${ }^{1 *}$ \\ ${ }^{1}$ Department of Biotechnology, Pukyong National University, Busan 48513, Republic of Korea \\ ${ }^{2}$ Aquafeed Research Center, NIFS, Pohang 46083, Republic of Korea \\ ${ }^{3}$ Department of Aquatic Life Medicine, Pukyong National University, Busan 48513, Republic of Korea \\ ${ }^{4}$ Aquaculture Research Division, NIFS, Busan 46083, Republic of Korea
}

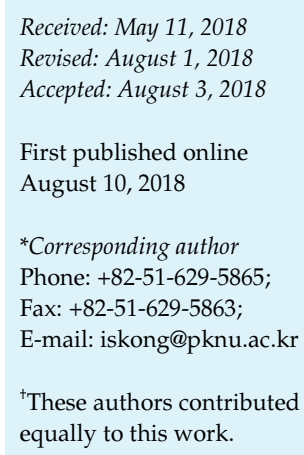

To identify and quantify the effects of a combination of dietary $1 \times 10^{8} \mathrm{CFU} / \mathrm{g}$ Lactococcus lactis subsp. lactis $\mathrm{I} 2\left(\mathrm{LI}_{2}\right)$ and $0.1 \%$-glucooligosaccharides (BGO) on the growth and immunity of olive flounder (Paralichthys olivaceus), a feeding experiment was conducted. Flounder (14 $\pm 0.5 \mathrm{~g})$ were divided into two groups and fed control and synbiotic feeds for 8 weeks. Investigations were carried out on growth and feed utilization, innate immunity, serum biochemical parameters, intestinal lactic acid bacterial (LAB) viability, microvillus length, and changes in the expression levels of genes encoding pro-inflammatory cytokines (tumor necrosis factor [TNF]- $\alpha$, interleukin [IL]-1 $\beta$, and IL-6). Results demonstrated the synbiotic diet had significantly better $(p<0.05)$ responses in terms of weight gain and specific growth rate, three innate immune parameters (respiratory burst, serum lysozyme, and superoxide dismutase), intestinal LAB viability, and the relative TNF- $\alpha$ expression level $(p<0.05)$. Moreover, after challenge with Streptococcus iniae $\left(1 \times 10^{8} \mathrm{CFU} / \mathrm{ml}\right)$, the synbiotically fed group exhibited significantly higher $(p<0.05)$ protection against streptococcosis, validating the observed changes in immune parameters and induction of the cytokine-encoding gene. Therefore, according to the results of the present study, synbiotic feed $\left(\mathrm{LI}_{2}+\mathrm{BGO}\right)$ increased growth, modulated innate immune parameters and protected olive flounder against streptococcosis.

Keywords: Synbiotic, growth performance, innate immunity, gene expression, olive flounder

\section{Introduction}

Olive flounder (Paralichthys olivaceus) is one of the most popular and commercially important fish species in fareast Asian countries including China, Japan, and Korea. Moreover, it is the foremost aquaculture species, with annual production reaching 41,636 tons and accounting for $51.1 \%$ of all aquaculture production in Korea [1] as the industry continues to grow day by day. However, largescale production increases the risk of infectious disease outbreaks, which can cause catastrophic production and economic losses. For example, in the past 5 years (2009-
2014), cumulative annual production in Korea has fallen by about 17,647 tons, because of such outbreaks [2], 32\% of which were caused by pathogenic bacteria with $19 \%$ by Streptococcus spp. [3].

In efforts to at least partially control bacterial infections, antibiotics like tetracycline, oxytetracycline, cephalosporin, erythromycin, and amoxicillin; chemotherapeutics like formalin, $\mathrm{NaCl}$ baths, and hydrogen peroxide; and various vaccines are very commonly used in aquaculture farms. However, repeated antibiotic use is associated with tet, erm, and mef activations in Streptococcus spp., creating tetracycline- and erythromycin-resistance by changing the 
target ribosomal subunit by methylation or mutation, modifying the antibiotic activity via enzyme-mediated antibiotic efflux [4]. Furthermore, antibiotics nonselectively destroy both harmful and beneficial microbes in aquatic environments, and their residues in aquaculture products pose worldwide food and health biosafety problems and compromise human health [5]. The negative effects of vaccine administration on olive flounder [6]; the development of antibiotic-resistant Streptococcus spp. in both the olive flounder [7] and humans [8], render it essential to develop biologically-safe alternative approaches (prebiotics, probiotics, and synbiotics) to improve fish immunity against pathogens of aquaculture facilities [9, 10]. Prebiotics are lowmolecular weight, non-digestible carbohydrates (usually oligosaccharides) that stimulate the growth and metabolism of beneficial intestinal bacteria [11]. Also, the administration of adequate concentrations of live bacteria to provide beneficial effects on growth and immunology of consumer is termed as probiotics [12]. Lactic acid bacteria (LAB) produce antimicrobial compounds such as nisin and pediocin [13] and directly inhibit the growth of Streptococcus iniae and other Gram-positive pathogenic bacteria [3, 14, 15]. Both the US Food and Drug Administration and the World Health Organization have approved such bacteria for use as probiotics for olive flounder. Moreover, intestinal LAB probiotics metabolize the usually indigestible prebiotics for growth stimulation and survival, and exert positive effects on the growth and immune status of the host [16]. Combinations of probiotics and prebiotics may exhibit additive, synergistic, or potentiation patterns termed as synbiotic [17], improving probiotic survival because the probiotic bacteria metabolize the prebiotic to a greater extent than do other intestinal bacteria. To the best of our knowledge, only one report on synbiotic supplementation of the diet of olive flounder (using Bacillus clausii with commercial prebiotics) has appeared [9]; no report had yet evaluated an LAB/prebiotic combination.

We earlier showed that nisin-Z-(bacteriocin) producing Lactococcus lactis subsp. lactis $\mathrm{I} 2\left(\mathrm{LI}_{2}\right)$ isolated from the intestine of olive flounder, and a $\beta$-glucooligosaccharides (BGO) from barley $\beta$-glucan, exhibited probiotic $\left(1 \times 10^{8}\right.$ CFU/g) [3] and prebiotic (0.1\%) [11] effects, respectively, in olive flounder. Moreover, in vitro, $\mathrm{LI}_{2}$ showed stimulated growth and survival associated with a $20 \%$ elevation in nisin- $\mathrm{Z}$ production by fermenting $0.1 \% \mathrm{BGO}$, as opposed to when glucose served as the growth substrate (our unpublished data). However, the potential of this synbiotic has not yet been evaluated in either a terrestrial or aquatic species.
Given the current problems in flounder aquaculture, and the potential of synbiotics, our objective was to develop an LAB-based synbiotic using a combination of $\mathrm{LI}_{2}$ and $\mathrm{BGO}$ at their previously reported conditions. We explored the effects of this synbiotic on flounder growth and innate immunity, and in terms of protection against streptococcosis.

\section{Materials and Methods}

All experimental activities in this research were performed following the guidelines of the Animal Ethics Committee Regulations, No. 554, issued by Pukyong National University, Busan, Republic of Korea.

\section{Feed Formulation}

Feed formulation and storage were performed as described by Bai and Kim [18]. Fishmeal, fish oil, and wheat flour were the protein, lipid, and carbohydrate sources, respectively (Table 1). After measuring and mixing all solid feed ingredients, fish oil and $30 \%(\mathrm{v} / \mathrm{w})$ water were added. Pelleting was performed using a 2-mm-diameter die by a pelleting machine (Baokyong Commercial Co., Korea). The feed was dried for $48-72 \mathrm{~h}$ at room temperature and stored at $-4^{\circ} \mathrm{C}$. To prepare a prebiotic-containing feed, the cellulose $(0.1 \%)$ of the control feed was replaced by $0.1 \%$ BGO.

Table 1. Composition of the basal experimental diet for olive flounder (Percent (\%) of dry matter (DM) basis).

\begin{tabular}{lc}
\hline \multicolumn{1}{c}{ Ingredients } & Percent (\%) \\
\hline Fish meal (herring) $^{\mathrm{a}}$ & 62.0 \\
Fish meal (tuna) $^{\mathrm{a}}$ & 10.5 \\
Wheat flour $^{\mathrm{b}}$ & 20.0 \\
Fish oil (menhaden) $^{\mathrm{b}}$ & 3.4 \\
Vitamin premix $^{\mathrm{c}}$ & 1.8 \\
\hline Mineral premix $^{\mathrm{d}}$ & 1.8 \\
\hline Cellulose $^{\mathrm{e}}$ & 0.5 \\
\hline Feed proximate composition analysis (\% DM) & \\
\hline Moisture & 9.19 \\
\hline Crude protein & 56.5 \\
\hline Crude lipid & 9.73 \\
\hline Crude ash & 12.8 \\
\hline
\end{tabular}

aSuhyup Feed Co., Uiryeong, Korea

${ }^{\mathrm{b}}$ The Feed Co., Goyang, Korea

'Contains (as mg/kg in diets): Ascorbic acid, 300; dl-Calcium pantothenate, 150; Choline bitate, 3000; Inositol, 150; Menadion, 6; Niacin, 150; Pyridoxine $\mathrm{HCl}, 15$; Rivoflavin, 30; Thiamine mononitrate, 15 ; dl- $\alpha$-Tocopherol acetate, 201; Retinyl acetate, 6; Biotin, 1.5; Folic acid, 5.4; Cobalamin, 0.06.

${ }^{\mathrm{d} C}$ Contains (as mg/kg in diets): $\mathrm{NaCl}, 437.4 ; \mathrm{MgSO}_{4} \cdot 7 \mathrm{H}_{2} \mathrm{O}, 1379.8 ; \mathrm{ZnSO}_{4} \cdot 7 \mathrm{H}_{2} \mathrm{O}$, 226.4; Fe-Citrate, 299; $\mathrm{MnSO}_{4}, 0.016 ; \mathrm{FeSO}_{4}, 0.0378 ; \mathrm{CuSO}_{4}, 0.00033 ; \mathrm{Ca}(\mathrm{IO})_{3}$, 0.0006; $\mathrm{MgO}, 0.00135 ; \mathrm{NaSeO}_{3}, 0.00025$.

ésigma-Aldrich Korea, Yongin, Korea 
The culture and addition of $\mathrm{LI}_{2}$ to the prebiotic feed was performed as described by Heo et al. [3]. Adjusted concentration of $\mathrm{LI}_{2}$ in PBS (pH 7.0, $0.1 \mathrm{M}$ ) was sprayed on the prebiotic feed every 3 days ( $\mathrm{LI}_{2}$ does not form spores), to ensure the presence of $1 \times 10^{8} \mathrm{CFU} / \mathrm{g}$ of $\mathrm{LI}_{2}$ in that prebiotic diet, totally formulated as a synbiotic feed. Feed and fish body proximate compositional analyses were performed by reference to the AOAC [19] recommended methods. Isonitrogenous and isoenergetic experimental diet formulations were prepared containing $56.5 \%$ crude protein, 9.73\% lipid, $9.19 \%$ moisture, and $12.8 \%$ ash (Table 1 ).

\section{Fish Husbandry and the Feeding Trial}

The feeding trial was performed in the Feeds and Foods Nutrition Research Center, Pukyong National University, Busan, Republic of Korea. Flounder were acclimated to the experimental environment, consuming control feed, for 14 days, and 10 flounders (body weight $14 \pm 0.5 \mathrm{~g}$ and total length $12 \pm 0.5 \mathrm{~cm}$ ) were then placed in each of six 40-L semi-recirculated seawater tanks and the two feeds (control and synbiotic) provided to each of three replicate tanks. The fish were given approximately $2.5-3 \%$ of their body weight of feed twice daily (at 9:00 and 17:00) for 8 weeks. During the entire trial, the water temperature, water flow, dissolved oxygen level, salinity, photoperiod, and $\mathrm{pH}$ were $17.5 \pm 0.5^{\circ} \mathrm{C}, 1.2 \mathrm{l} / \mathrm{min}, 7.0 \mathrm{mg} / \mathrm{l}, 32 \pm 1 \mathrm{ppt}, 12$-h light:12-h dark, and $7.4 \pm 0.5$, respectively.

\section{Sample Collection}

At the end of the trial, all fish were weighed and weight gains (WG) and feed utilization parameters (feed efficiency ratio and protein efficiency ratio) calculated. Three fish randomly selected from each tank (9 fish/group) were anesthetized in $500 \mu \mathrm{l} / 12$ phenoxyethanol (Sigma-Aldrich, USA), and their lengths and weights were measured for condition factor $(\mathrm{CF})$ calculations. Then, blood was collected from the caudal vein using heparinized and non-heparinized syringes. Serum was prepared from clotted blood by centrifugation at $5,000 \times g$ for $10 \mathrm{~min}$ and stored at $-79^{\circ} \mathrm{C}$. After that, the livers and intestines of the fish were weighed to allow calculation of the viscerosomatic and hepatosomatic indices (VSI and HSI); these tissues, along with the fish carcasses, underwent proximate composition analyses.

\section{Estimation of Feed $\mathrm{LI}_{2}$ and Intestinal LAB Viabilities}

We used a slight modification of the method of Nikoskelainen et al. [20] to measure LAB viability in feed and fish intestines. Onegram amounts of feed were mixed with $9 \mathrm{ml}$ (10-fold dilution) of PBS ( $\mathrm{pH} 7.0,0.1 \mathrm{M}$ ) and held at room temperature for $10 \mathrm{~min}$. After simple vortexing, the suspension was held at room temperature for a further $7-8 \mathrm{~min}$ to allow the feed to settle. Then, 1 -ml amounts of supernatant were serially diluted and spread on lactobacilli selective MRS (de Man, Rogosa \& Sharpe Merck, Germany) agar plates, incubated in $37^{\circ} \mathrm{C}$ for $24 \mathrm{~h}$ and colonies were counted. To determine intestinal LAB viability, one fish per tank ( 3 fish/group) was starved for $24 \mathrm{~h}$, anesthetized, and $1 \mathrm{~g}$ of intestinal tissue was collected, cut into small pieces, ground well, and then $0.5 \mathrm{~g}$ of ground tissue was diluted with $4.5 \mathrm{ml}$ of PBS, and processed as described above for the feed samples.

\section{Innate Immune Parameters and Serum Biochemical Parameters}

The turbidometric assay used to determine serum lysozyme activity was that of Ellis [21], with slight variations. Briefly, 190- $\mu$ l of a $0.2 \mathrm{mg} / \mathrm{ml}$ lyophilized Micrococcus lysodeikticus (SigmaAldrich, USA) suspension in PBS (pH 6.2, $0.05 \mathrm{M}$ ) were added to wells of a $96-$-well plate and $10-\mu$ l of serum were then added. Absorbances were read at $530 \mathrm{~nm}$ after incubation at room temperature for 0.5 and $4.5 \mathrm{~min}$ by a microplate reader (Infinite M200 nanoquant, Tecan, Zurich, Switzerland). One unit of lysozyme activity corresponded to a reduction in absorbance of $0.001 / \mathrm{min}$.

Superoxide dismutase (SOD) activities in 20- $\mu$ l of serum were measured using an SOD assay kit (K335-100, BioVision, USA) according to the manufacturer's instructions. SOD inhibited the action of xanthine oxidase on a water-soluble tetrazolium dye. Absorbances at $450 \mathrm{~nm}$ were read after $20 \mathrm{~min}$ reaction at $37^{\circ} \mathrm{C}$ and percentage inhibitions calculated using absorbance reading through a kit optimized equation.

Serum myeloperoxidase (MPO) activity was estimated using the method of Quade and Roth [22], with slight modifications. Serum samples $(20 \mu \mathrm{l})$ were diluted with $80-\mu \mathrm{l}$ of Hanks' balanced salt solution (without $\mathrm{Ca}^{2+}$ or $\mathrm{Mg}^{2+}$ ) in wells of a 96-well plate and $35 \mu \mathrm{l}$ of $20 \mathrm{mM} 3,3^{\prime}, 5,5^{\prime}$-tetramethylbenzidine hydrochloride (TMB, Sigma-Aldrich, USA) and $35 \mu \mathrm{l}$ of $5 \mathrm{mM} \mathrm{H}_{2} \mathrm{O}_{2}$ were added to each well. After 2 min of incubation, $35 \mu \mathrm{l}$ of $4 \mathrm{M} \mathrm{H}_{2} \mathrm{SO}_{4}$ was added to stop the color change and the absorbance read at $450 \mathrm{~nm}$.

The generation of oxidative radicals by neutrophils engaging in phagocytic activity during a respiratory burst was measured with the aid of the nitroblue-tetrazolium (NBT) assay, as described by Hasan et al. [11], and serum antiprotease levels were estimated using the method of Heo et al. [3].

Total cholesterol, serum alanine aminotransferase (ALT), serum total glucose, serum protein and aspartate aminotransferase (AST) levels were determined with the aid of an autoanalyzer (Fuji DRICHEM 3500i, Fuji Photo Film, Ltd., Japan).

\section{Reverse Transcriptase Polymerase Chain Reaction (RT-PCR) and Middle Intestinal Histopathology}

To quantify the effects of synbiotic feeding on the levels of tumor necrosis factor (TNF)- $\alpha$, interleukin (IL)-1 $\beta$, and IL-6 in four distinct organs (liver, kidney, gill and spleen) RT-PCR was performed. Organ samples were collected from 1 fish per tank ( 3 fish/group) and we performed RT-PCR as described by Hasan et al. [11]. Briefly, 55-60-mg of organ tissues were homogenized in 1-ml of Ambion Trizol (Thremo Fisher Scientific, USA) under sterile conditions, and RNA was extracted according to the instructions of the manufacturer. The RNAs were treated with DNase-I to remove genomic DNA, following the protocol of a DNase kit (Riboclear plus, GeneAll, Korea). RNA purity (OD 
Table 2. Gene specific primers, annealing temperature, gene bank accession number ${ }^{\mathrm{a}}$ and cycle number ${ }^{\mathrm{b}}$ of olive flounder $\beta$-actin and cytokines genes used in this study.

\begin{tabular}{|c|c|c|c|c|}
\hline Name of gene & Sense & Oligonucleotide Sequence (5' to $3^{\prime}$ ) & Base pair (bp) & Annealing temperature $\left({ }^{\circ} \mathrm{C}\right)$ \\
\hline \multirow[t]{2}{*}{$\beta$-actin } & $\mathrm{F}$ & TTTCCCTCCATTGTTGGTCG & 200 & 58 \\
\hline & $\mathrm{R}$ & GCGACTCTCAGCTCGTTGT & & \\
\hline \multirow[t]{2}{*}{ TNF- $\alpha$} & $\mathrm{F}$ & CAGCTGCAGCTCAGCAGGCACCTGGAGAC & 168 & 60 \\
\hline & $\mathrm{R}$ & GGACGACTTCTTCTCCACCAGAACC & & \\
\hline \multirow[t]{2}{*}{ IL-1 $\beta$} & $\mathrm{F}$ & ATGGAATCCAAGATGGAATGC & 250 & 57 \\
\hline & $\mathrm{R}$ & GAGACGAGCTTCTCTCACAC & & \\
\hline \multirow[t]{2}{*}{ IL-6 } & $\mathrm{F}$ & CGAATACGAGCCCACCGACAGTCC & 460 & 58 \\
\hline & $\mathrm{R}$ & GTGGAAAGTGCTGGGGTTGTGG & & \\
\hline
\end{tabular}

${ }^{\mathrm{a}}$ Gene bank accession number: $\beta$-actin (HQ386788.1), TNF- $\alpha$ (AB040448.1), IL-1 $\beta$ (AB070835.1), IL-6 (DQ267937.1).

${ }^{\mathrm{b}}$ Cycle numbers: 30

260:280) and concentration (ng/ $\mu$ l) were measured via NanoDrop (Thremo Fisher Scientific, USA) spectrometry and 1- $\mu$ g of RNA were used for cDNA synthesis employing a kit protocol (PrimeScript, Takara, Japan) as instructed by the manufacturer. PCR was performed on an equivalent of cDNA using gene-specific primers (Table 2) and the products were electrophoresed on a $1.5 \%(\mathrm{w} / \mathrm{v})$ agarose gel. The photostimulated luminescence values of PCR bands were measured with the aid of ImageJ software (version 1.38; National Institutes of Health, USA). The relative levels of RNAs encoding various cytokines were determined and normalized to those encoding endogenous $\beta$-actin.

Fishes used for RT-PCR (3 fish/group) were also used for middle intestine histopathology evaluation as described by Abid et al. [23]. Photographs were taken by a light microscope (Olympus BX50, Japan) and microvillus length was determined with the aid of Image-Pro Plus software (Version 5.1, Germany).

\section{Challenge Test}

At the end of the feeding trial, five fish from each ( 15 fish/group) tank were anesthetized, intraperitoneally injected with $100-\mu$ of an S. iniae (KCTC 3657) suspension at a concentration of $1 \times 10^{8}$ $\mathrm{CFU} / \mathrm{ml}[3,11]$, and kept in quarantine tanks without water exchange or feeding. Fish condition and mortality were checked every $6 \mathrm{~h}$ daily up to 14 days. Streptococcosis was confirmed by the growth of $S$. iniae on brain heart infusion (BHI) agar plates after spreading of swabs from the skins, livers, and gills of dead fish. We calculated survival as:

Survival $(\%)=[($ Initial fish number - Dead fish number $) /$ Initial fish number] $\times 100$

\section{Statistical Analysis}

The normality and variance homogeneity of the datasets were checked by Shaprio-Wilk and Levene tests, respectively. Before analysis, non-normally distributed data were log-transformed through Kruskal-Wallis test. All data were analyzed with the aid of IBM SPSS software (SPSS Inc., version 17.0, USA). One-way
ANOVA (Analysis of variance) was used to determine if parameters of the control and synbiotic groups differed significantly. A $p$ value $<0.05$ was considered to reflect significance and values are presented as means \pm standard deviations (SD).

\section{Results}

Effect of the Synbiotic on Growth, Feed Utilization, and Body Indices

The WG and specific growth rate (SGR) values of the

Table 3. Growth, feed utilization and body indices of olive flounder fed with experimental diets for 8 weeks

\begin{tabular}{cccc}
\hline \multicolumn{3}{c}{ Diets } \\
\hline $\begin{array}{c}\text { Growth } \\
\text { Parameters }\end{array}$ & Control & Synbiotic & $\begin{array}{c}\text { Level of } \\
\text { significance } \\
(p \text {-value })^{\mathrm{a}}\end{array}$ \\
\hline $\mathrm{WG}^{\mathrm{b}}$ & $222.90 \pm 6.68$ & $252.74 \pm 5.61$ & $\mathrm{~S}$ \\
$\mathrm{SGR}^{\mathrm{c}}$ & $2.09 \pm 0.08$ & $2.24 \pm 0.04$ & $\mathrm{~S}$ \\
$\mathrm{FER}^{\mathrm{d}}$ & $117.53 \pm 6.46$ & $125.62 \pm 3.17$ & $\mathrm{NS}$ \\
$\mathrm{PER}^{\mathrm{e}}$ & $2.07 \pm 0.11$ & $2.23 \pm 0.05$ & $\mathrm{NS}$ \\
$\mathrm{CF}^{\mathrm{f}}$ & $0.84 \pm 0.02$ & $0.87 \pm 0.05$ & $\mathrm{NS}$ \\
$\mathrm{VSI}^{\mathrm{g}}$ & $3.22 \pm 0.26$ & $3.31 \pm 0.14$ & $\mathrm{NS}$ \\
$\mathrm{HSI}^{\mathrm{h}}$ & $1.37 \pm 0.25$ & $1.50 \pm 0.13$ & $\mathrm{NS}$ \\
\hline
\end{tabular}

${ }^{a}$ Values are mean \pm SD of three replicates (3 fish/replicate). "S" or "NS" indicates values within the same row in the table are significantly $(p<0.05)$ or not significantly $(p>0.05)$ different, respectively.

${ }^{b}$ WG: Weight gain $(\%)=[($ Final weight - Initial weight $) /$ Initial weight $\left.)\right] \times 100$. 'SGR: Specific growth rate $(\% /$ day $)=[(\ln$ final weight $-\ln$ initial weight $) /$ days $]$ $\times 100$.

${ }^{\mathrm{d}}$ FER: Feed efficiency ratio $(\%)=($ Wet weight gain $/$ Dry feed intake $) \times 100$. ${ }^{e}$ PER: Protein efficiency ratio $=$ Wet weight gain $/$ Protein fed.

${ }^{\mathrm{f}} \mathrm{CF}$ : Condition factor $(\%)=\left[\right.$ Body weight $\left.(\mathrm{g}) /\{\text { Total body length }(\mathrm{cm})\}^{3}\right] \times 100$. ${ }^{g}$ VSI: Viscerosomatic Index $(\%)=($ Visceral weight $/$ Body weight $) \times 100$. ${ }^{\mathrm{h}}$ HSI: Hepatosomatic Index $(\%)=($ Liver weight $/$ Body weight $) \times 100$. 
Table 4. Olive flounder initial and final body proximate composition.

\begin{tabular}{|c|c|c|c|c|}
\hline \multicolumn{5}{|c|}{ Proximate analysis (\% of DM basis) } \\
\hline \multirow{2}{*}{ Nutrient composition } & \multirow[t]{2}{*}{ Initial } & \multicolumn{2}{|c|}{ Final } & \multirow{2}{*}{ Level of significance ( $p$-value) ${ }^{\mathrm{a}}$} \\
\hline & & Control & Synbiotic & \\
\hline Moisture & $76.76 \pm 1.43$ & $74.47 \pm 1.64$ & $74.81 \pm 1.35$ & NS \\
\hline Crude protein & $16.67 \pm 0.63$ & $18.51 \pm 1.15$ & $18.51 \pm 1.15$ & NS \\
\hline Crude lipid & $3.25 \pm 0.78$ & $3.26 \pm 0.15$ & $3.26 \pm 0.15$ & NS \\
\hline Crude ash & $3.99 \pm 0.20$ & $3.53 \pm 0.28$ & $3.53 \pm 0.28$ & NS \\
\hline
\end{tabular}

${ }^{a}$ Values are mean \pm SD of three replicates ( 3 fish/replicate). "NS" indicates values within the same row in the table are not significantly different ( $p>0.05$ ).

synbiotic group were significantly higher $(p<0.05)$ than the control group (Table 3). However, fish body indices (CF, HSI, and VSI) or feed utilization parameters were unchanged compared with control after 56 days of feeding trial. Moreover, the synbiotic feed did not affect $(p>0.05)$ flounder body proximate composition (Table 4).

\section{LAB Viability in Feed and the Intestine}

After spray, the $\mathrm{LI}_{2}$ concentration in the synbiotic feed was more or less constant for three days, averaging $9.73 \times 10^{7} \mathrm{CFU} / \mathrm{g}\left(\sim 1 \times 10^{8} \mathrm{CFU} / \mathrm{g}\right)$. In control fish, the intestinal $\mathrm{LAB}$ count was too few to count (TFTC, $<30 \mathrm{CFU} / \mathrm{ml})$, but that in fish fed the synbiotic averaged $\sim 3.91 \times 10^{4} \mathrm{CFU} / \mathrm{g}(p<0.05)$.

Effects of the Synbiotic on Non-Specific Immune and Serum Biochemical Parameters

Among five innate immune parameters three were

Table 5. Non-specific immune responses of olive flounder fed the experimental diets for 8 weeks.

\begin{tabular}{lccc}
\hline \multicolumn{1}{c}{ Diets } \\
$\begin{array}{c}\text { Innate } \\
\text { Immunity } \\
\text { Parameters }\end{array}$ & Control & Synbiotic & $\begin{array}{c}\text { Level of } \\
\text { significance } \\
(p \text {-value })^{\mathrm{a}}\end{array}$ \\
\hline $\mathrm{RB}^{\mathrm{b}}$ & $0.38 \pm 0.02$ & $0.48 \pm 0.03$ & $\mathrm{~S}$ \\
$\mathrm{SOD}^{\mathrm{c}}$ & $60.03 \pm 3.29$ & $76.79 \pm 1.94$ & $\mathrm{~S}$ \\
LSZ $^{\mathrm{d}}$ & $307.33 \pm 14.75$ & $456.66 \pm 11.27$ & $\mathrm{~S}$ \\
MPO $^{\mathrm{e}}$ & $1.57 \pm 0.23$ & $1.84 \pm 0.17$ & $\mathrm{NS}$ \\
Antiprotease $^{\mathrm{f}}$ & $73.28 \pm 2.39$ & $77.19 \pm 1.98$ & $\mathrm{NS}$ \\
\hline
\end{tabular}

a Values are mean \pm SD of three replicates (3 fish/replicate). "S" or "NS" indicates values within the same row in the table are significantly $(p<0.05)$ or not significantly $(p>0.05)$ different, respectively.

${ }^{\mathrm{b}} \mathrm{RB}$ : Respiratory burst (Absorbance at 540nm)

'SOD: Superoxide dismutase (\% Superoxide inhibition)

${ }^{\mathrm{d}}$ LSZ: Serum lysozyme activity (Units/ml)

${ }^{e}$ MPO: Myeloperoxidase activity (Absorbance at 450nm)

${ }^{\mathrm{f}}$ Antiprotease: Percent (\%) of Trypsin inhibition upregulated by synbiotic inoculated feed. Table 5 clearly illustrated, serum lysozyme activity, respiratory burst, and SOD inhibition percentage in the synbiotic group were significantly higher $(p<0.05)$ than the control group. The synbiotic had no effect on serum antiprotease and MPO activity. Also, all serum biochemical parameters including the ALT and AST levels were very similar $(p>0.05)$ in both groups depicted in Table 6.

\section{Effects of the Synbiotic on Cytokine Gene Expression Levels and Microvillus Length}

Fig. 1A shows that, in the synbiotic group, only the levels of mRNA encoding TNF- $\alpha$ in liver and spleen were higher (by about 1.70-fold) than the control levels (Fig. 1B) $(p<$ $0.05)$. However, the TNF- $\alpha$ expression levels in gills and kidneys, and the IL-1 $\beta$ (Fig. 1C) and IL-6 (Fig. 1D) expression levels in all organs, were not affected $(p>0.05)$ by the synbiotic. In addition, the microvillus lengths were $1.66 \pm 0.14$ and $1.72 \pm 0.20 \mu \mathrm{m}$ in the control (Fig. 2A) and synbiotic (Fig. 2B) groups respectively, thus mid-intestinal microvillus length and structure were not affected by synbiotic feeding for 8 weeks.

Table 6. Serum biochemical parameters of olive flounder fed the experimental diets for 8 weeks

\begin{tabular}{lccc}
\hline \multicolumn{3}{c}{ Diets } \\
\hline Biochemical Parameters & Control & Synbiotic & $\begin{array}{c}\text { Level of } \\
\text { significance } \\
(p \text {-value })^{\mathrm{a}}\end{array}$ \\
\hline $\mathrm{ALT}^{\mathrm{b}}(\mathrm{U} / \mathrm{l})$ & $28.00 \pm 2.64$ & $29.04 \pm 4.00$ & $\mathrm{NS}$ \\
AST $^{\mathrm{c}}(\mathrm{U} / \mathrm{l})$ & $11.39 \pm 3.05$ & $11.00 \pm 2.64$ & $\mathrm{NS}$ \\
Total Glucose $(\mathrm{mg} / \mathrm{dl})$ & $71.00 \pm 5.56$ & $72.66 \pm 2.51$ & $\mathrm{NS}$ \\
Total Cholesterol $(\mathrm{mg} / \mathrm{dl})$ & $228.33 \pm 4.16$ & $232.33 \pm 3.71$ & $\mathrm{NS}$ \\
Serum Protein $(\mathrm{mg} / \mathrm{ml})$ & $56.71 \pm 3.80$ & $58.23 \pm 2.26$ & $\mathrm{NS}$ \\
\hline
\end{tabular}

"Values are mean \pm SD of three replicates (3 fish/replicate). "NS" indicates values within the same row in the table are not significantly different $(p>0.05)$.

${ }^{\mathrm{b}}$ ALT: Alanine aminotransferase

${ }^{c}$ AST: Aspartate aminotransferase 
A

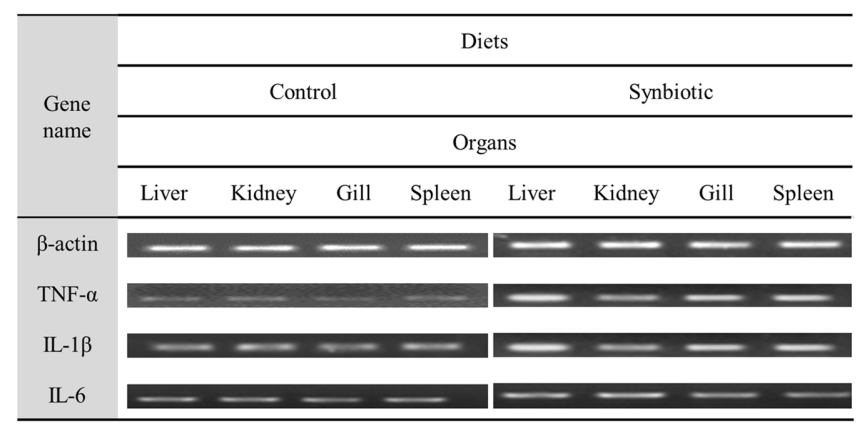

C

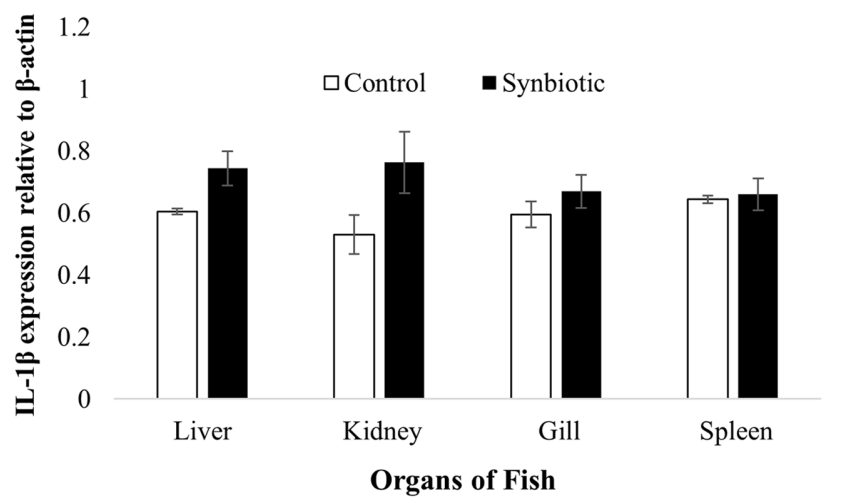

B

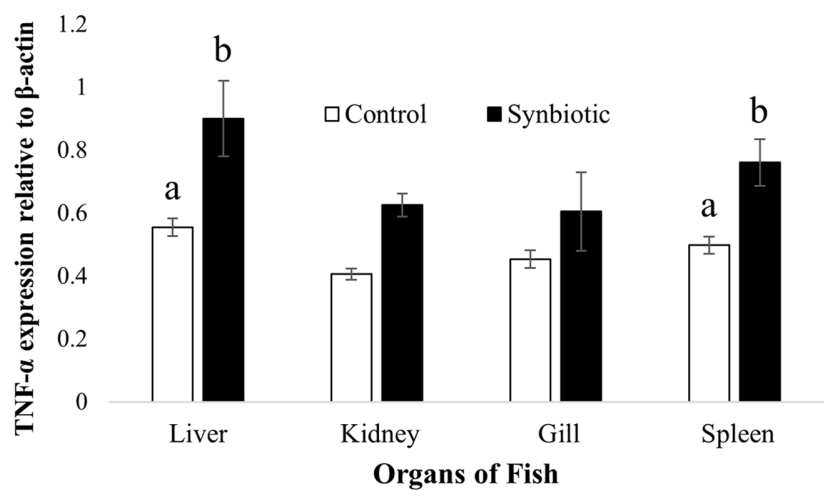

D

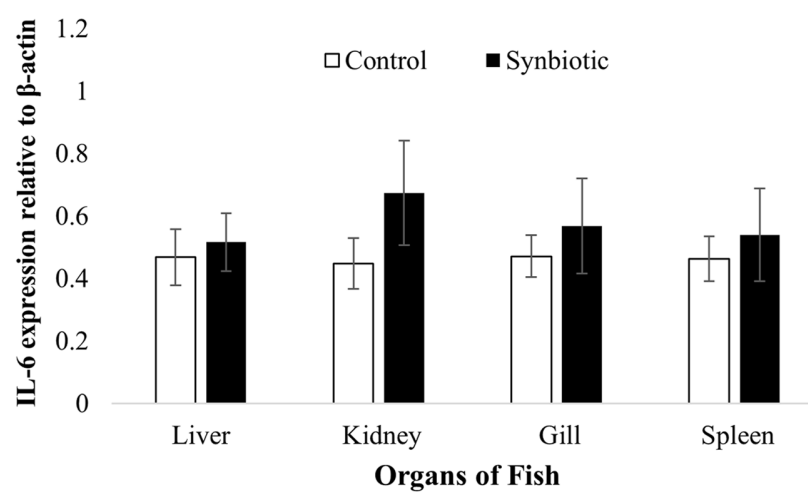

Fig. 1. Relative expression levels of genes encoding various cytokines in olive flounder fed a control or synbiotic diet for 56 days. RT-PCR was used to quantify gene expression levels in various organs (A). Densitometric quantification of mRNAs encoding tumor necrosis factor (TNF)- $\alpha$ (B); interleukin (IL)-1 $\beta$ (C); and IL-6 (D), relative to that of mRNA encoding $\beta$-actin, in livers, kidneys, gills, and spleens. Data represent means \pm standard deviations, and means with different letters differed significantly $(p<0.05)$. The lack of letter indicates that the difference was not significant $(p>0.05)$.

\section{Cumulative Mortality after S. iniae Challenge}

The first deaths in the control and synbiotic groups occurred at 7 and 8 days, respectively, after challenge with S. iniae. Moreover, after about 10 days control group mortality attained $100 \%$, but at 14 days the synbiotic group survival proportion was $20 \%$, thus significantly better $(p<$ 0.05 ) than that of the control group (Fig. 3), although both groups had been identically (S. iniae; $1 \times 10^{8} \mathrm{CFU} / \mathrm{ml}$ ) challenged.

\section{Discussion}

In this present study, synbiotic-fed olive flounder group showed positive WG and SGR compared with those in the control group. Similar results were demonstrated by some previous reports on LAB synbiotics, supplemented to rockfish (Sebastes schlegeli) [10], basa fish (Pangasius bocourti)
[24], and juvenile Siberian sturgeon (Acipenser baerii) [25]. However, supplementation with individual $\mathrm{LI}_{2}\left(1 \times 10^{8}\right.$ $\mathrm{CFU} / \mathrm{g})$ or BGO $(0.1 \%)$ depicted no improvement of WG in olive flounder $[3,11]$. The fish innate immune system is a key weapon when combating foreign invaders. Several types of blood cells (neutrophils, monocytes, and macrophages) act with cytokines to engulf, kill, and eradicate pathogens. Moreover, after synbiotic feeding, microbial fermentation of prebiotic produces short-chain fatty acids that bind to Gprotein receptors (GPR43), modulating immune parameters [26]. During macrophage and neutrophil phagocytosis in the course of a respiratory burst, oxygen $\left(\mathrm{O}_{2}\right)$ is converted to superoxide $\left(\mathrm{O}_{2}^{-}\right)$and $\mathrm{MPO}$ then transforms $\mathrm{O}_{2}^{-}$to hypochlorous acid $(\mathrm{HClO})$. Both $\mathrm{O}_{2}^{-}$and $\mathrm{HClO}$ are bactericidal, aiding in pathogen destruction and eradication [27]. However, the highly reactive $\mathrm{O}_{2}^{-}$anion is also toxic to host cells, and is converted to the less reactive $\mathrm{H}_{2} \mathrm{O}_{2}$, and 

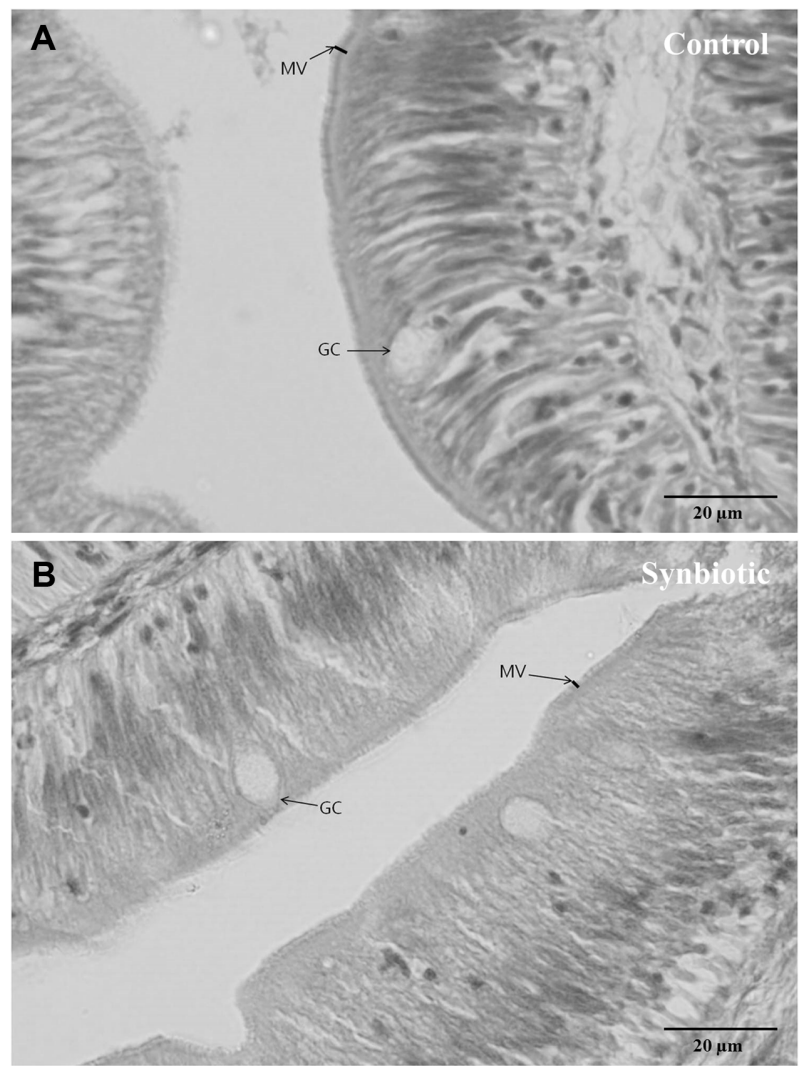

Fig. 2. Mid-intestinal histopathology of olive flounder fed without (A) or with synbiotic supplement (B) for 56 days.

Pictures were taken with a light microscope, MV: microvilli; GC: goblet cell; light microscopy staining: hematoxylin and eosin. Scale bars $20 \mu \mathrm{m}$ (A and $\mathbf{B})$.

finally water, by SOD activity. Importantly, fish lysozyme cleaves not only the $\beta$-(1,4)-linked $\mathrm{N}$-acetylglucosamine and $\mathrm{N}$-acetylmuramic acid of Gram-negative bacteria [28], but also destroys all types of pathogenic bacteria engulfed by macrophages or neutrophils [29]. The significant changes in lysozyme activity, the respiratory burst, and the SOD level constitute clear evidence that the synbiotic exercised immunomodulatory effects through positive alteration of different immune cells and enzymes activities in our olive flounder. Similarly, feeding of synbiotics to olive flounder [9]; cobia (Rachycentron canadum) [30]; Atlantic salmon (Salmo salar) [23] and rainbow trout [31] over various periods was accompanied by positive changes in innate immune parameters. In contrast, feeding with various graded levels of a synbiotic (B. subtitis + FOS) to juvenile large croaker (Larimichthys crocea) did not modulate their immunological status [32].

Immune system-related cytokines generally act in cascades.

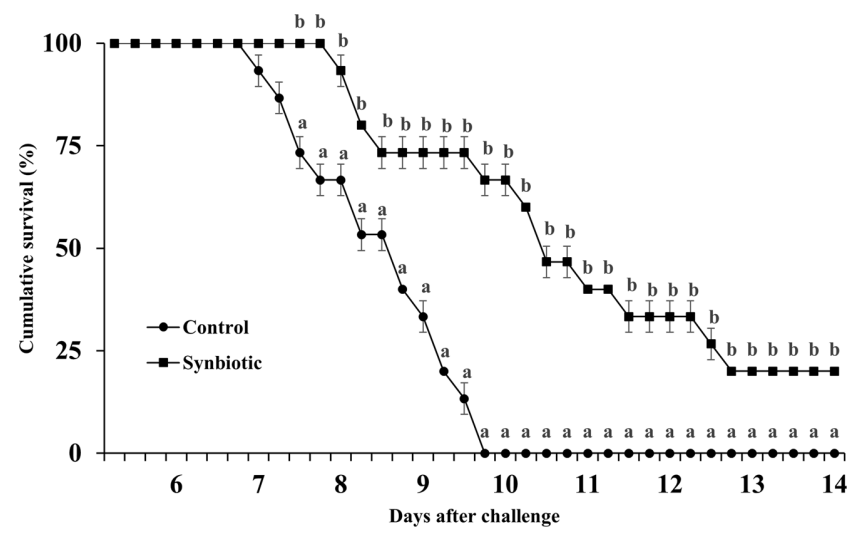

Fig. 3. Cumulative survival rates of olive flounder after challenge with Streptococcus iniae $\left(1 \times 10^{8} \mathrm{CFU} / \mathrm{ml}\right)$.

Means were compared at identical times; means with different or lack of letters indicates significant $(p<0.05)$ or non-significant differences $(p>0.05)$ respectively.

LAB can activate dendritic cells, specifically the $T_{\mathrm{H}} 1$ subset $\mathrm{CD}^{+} \mathrm{T}$, which stimulates pro-inflammatory gene expression to eliminate invasive pathogens during the acute phase of the immune response [15]. Cytokine expression profiles reflect the extent of their involvement in immune defense, and such expression is sometimes associated with variations in other immune parameters. TNF- $\alpha$ is an immune system biomarker that orchestrates the host defense against pathogen invasion and colonization [33]. TNF- $\alpha$ is secreted principally by activated macrophages and stimulates neutrophil-associated immunity [34]. In this study, it is possible that the significant changes in the blood respiratory burst (NBT assay) and TNF- $\alpha$ expression levels in liver and spleen after synbiotic feeding may be interrelated because the NBT assay measures neutrophil activation and proliferation. TNF- $\alpha$ expression in olive flounder showed a positive correlation with innate immunity after feeding with LAB [15] and LAB synbiotic fed to Atlantic salmon [23] have been studied and the results were similar to present study. As previously stated by Dziarski [35], after peptidoglycan (LAB cell wall component) binding with the specific sites of macrophage and lymphocyte, they get activated and stimulated, which could cause secretion of TNF- $\alpha$. Moreover, the liver and spleen are enriched with different types of immune cells including macrophages and lymphocytes $[36,37]$. Probably this is the reason why these two organs showed higher mRNA transcription levels of TNF- $\alpha$ in the present study. However, very high levels of TNF- $\alpha$ is also undesirable for cells [38]. Moreover, as in this study, an 8 -week feeding trial of $0.1 \% \quad \beta$-glucan plus 
$10^{9} \mathrm{CFU} / \mathrm{g}$ Shewanella putrefaciens had no effect on IL-1 $\beta$ expression in the head-kidney of gilthead seabream (Sparus aurata) [39].

It is generally assumed that a greater microvillus length in the apical brush border may improve nutrient uptake and improved the apparent digestibility coefficient. Similar to our current finding, a 63-day synbiotic feeding trial in Atlantic salmon had no effect on microvillus length in the posterior intestine [23]. However, Zhou et al. [40] reported that only prebiotics increased microvillus length in the middle intestine of red drum (Sciaenops ocellatus). It is not clear, but lack of alteration in metabolism governing IL-6 [41] and MVL by synbiotic feeding might explain the no effect on FER and PER in this study. In the cited study, the significantly higher LAB levels in intestines of the synbiotic group reflected microbial community alterations positively affecting both growth and innate immunity [42], or innate immunity only [20], in agreement with our present findings. Serum ALT is a biomarker of liver dysfunction or damage, and AST is expressed by kidney, liver, skeletal and cardiac tissue. Cellular degradation caused by stress or toxins triggers high-level ALT and AST release into the bloodstream. The absence of changes in ALT and AST levels indicates that our synbiotic is safe for aquaculture feeding. Oral administration of $0.1 \%$ BGO had no effects on ALT and AST levels in olive flounder [11]; and a combination of Enterobacter faecium with $0.1 \%$ FOS did not affect the levels of triglyceride or total glucose, or the albumin:globulin ratio, in rainbow trout [43].

LAB may inhibit fish pathogens by producing a bacteriocin, lactic acid, or another antibacterial compound [44]. The feeding of synbiotics to cobia [30] and rainbow trout [31] afforded significant resistance against Vibrio harveyi and S. iniae infections, respectively. We found that fish fed the synbiotic were significantly protected against streptococcosis. It was previously shown that a single administration of $1 \times 10^{8} \mathrm{CFU} / \mathrm{g} \mathrm{LI}_{2}$ or $0.1 \%$ BGO to olive flounder that were then challenged with $1 \times 10^{8} \mathrm{CFU} / \mathrm{ml}$ S. iniae was associated with $100 \%$ mortality in 12 and 11 days, respectively $[3,11]$ whereas the combination $\left(\mathrm{LI}_{2}+\mathrm{BGO}\right)$ improved survival duration and percentages ( $20 \%$ survival at 14 days). Such protection against streptococcosis may reflect BGO fermentation by $\mathrm{LI}_{2}$ for stimulating growth in the intestine, positively affecting the immune parameters of olive flounder. Thus the relationship between $\mathrm{BGO}$ and $\mathrm{LI}_{2}$ appeared to be very effective when they were combined to create a synbiotic.

According to the findings of this research, the combination of $\mathrm{LI}_{2}$ and $\mathrm{BGO}$ (LAB-based synbiotic) supplement not only improved fish growth, innate immunological parameters, TNF- $\alpha$ transcription, and intestinal microbial community but also protected fishes from streptococcosis. In future, this newly identified synbiotic feeding strategy could be implemented in field level to encourage fish farmers to cease antibiotic use in aquaculture practices, in turn ensuring food and nutritional biosafety. Various mixtures of $\mathrm{LI}_{2}$ and $\mathrm{BGO}$ should be tested in the future to establish an optimum dietary synbiotic for the olive flounder.

\section{Acknowledgment}

This work was financially supported by the grant (R20180003) from the National Institute of Fisheries Science (NIFS), Republic of Korea.

\section{Conflict of Interest}

The authors have no financial conflicts of interest to declare.

\section{References}

1. Statistics Korea (KOSTAT): Republic of Korea: 2016 Survey on the status of fish culture (Proposed). Available from http:/ / kostat.go.kr/portal/korea/kor_nw/2/7/1/index.board? bmode $=$ read\&aSeq $=359717$

2. Norwood C. (World Aquaculture Society's 2015 annual conference) Flatfish spearhead South Korea' saquaculture exports. FISH 23: 28-29. Available from http://www.frdc. com.au/knowledge/publications/fish/Pages/23-3_articles / 28-Flatfish-spearhead.aspx\#sthash.MRckN1r1.dpuf

3. Heo WS, Kim YR, Kim EY, Bai SC, Kong IS. 2013. Effects of dietary probiotic, Lactococcus lactis subsp. lactis I2, supplementation on the growth and immune response of olive flounder (Paralichthys olivaceus). Aquaculture 376: 20-24.

4. Park YK, Nho SW, Shin GW, Park SB, Jang HB, Cha IS, et al. 2009. Antibiotic susceptibility and resistance of Streptococcus iniae and Streptococcus parauberis isolated from olive flounder (Paralichthys olivaceus). Vet. Microbiol. 136: 76-81.

5. World Health Organization (WHO). 2006 Report of a joint FAO/OIE/WHO expert consultation on antimicrobial use in aquaculture and antimicrobial resistance. Seoul, Republic of Korea, 13-16 June, 2006.

6. Kwon SR, Lee EH, Nam YK, Kim SK, Kim KH. 2007. Efficacy of oral immunization with Edwardsiella tarda ghosts against edwardsiellosis in olive flounder (Paralichthys olivaceus). Aquaculture 269: 84-88.

7. Baeck GW, Kim JH, Gomez DK, Park SC. 2006. Isolation and characterization of Streptococcus sp. from diseased flounder (Paralichthys olivaceus) in Jeju Island. J. Vet. Sci. 7: 53-58. 
8. Facklam R, Elliott J, Shewmaker L, Reingold A. 2005. Identification and characterization of sporadic isolates of Streptococcus iniae isolated from humans. J. Clin. Microbiol. 43: 933-937.

9. Ye JD, Wang K, Li FD, Sun YZ. 2011. Single and combined effects of fructo- and mannan oligosaccharide supplements and Bacillus clausii on the growth, feed utilization, body composition, digestive enzyme activity, innate immune response and lipid metabolism of Japanese flounder Paralichthys olivaceus. Aquacult. Nutr. 17: e902-e911.

10. Rahimnejad S, Guardiola FA, Leclercq E, Esteban MÁ, Castex M, Sotoudeh E, et al. 2018. Effects of dietary supplementation with Pediococcus acidilactici MA18/5M, galactooligosaccharide and their synbiotic on growth, innate immunity and disease resistance of rockfish (Sebastes schlegeli). Aquaculture 482: 36-44.

11. Hasan MT, Jang WJ, Lee S, Kim KW, Lee BJ, Han HS, et al. 2018. Effect of $\beta$-glucooligosaccharides as a new prebiotic for dietary supplementation in olive flounder (Paralichthys olivaceus) aquaculture. Aquac. Res. 49: 1310-1319.

12. Hill C, Guarner F, Reid G, Gibson GR, Merenstein DJ, Pot B, et al. 2014. Expert consensus document: the international scientific association for probiotics and prebiotics consensus statement on the scope and appropriate use of the term probiotic. Nat. Rev. Gastro. Hepat. 11: 506-514.

13. Bari ML, Ukuku DO, Kawasaki T, Inatsu Y, Isshiki K, Kawamoto S. 2005. Combined efficacy of nisin and pediocin with sodium lactate, citric acid, phytic acid, and potassium sorbate and EDTA in reducing the Listeria monocytogenes population of inoculated fresh-cut produce. J. Food Protect. 68: 1381-1387.

14. Kim D, Beck BR, Heo SB, Kim J, Kim HD, Lee SM, et al. 2013. Lactococcus lactis BFE920 activates the innate immune system of olive flounder (Paralichthys olivaceus), resulting in protection against Streptococcus iniae infection and enhancing feed efficiency and weight gain in large-scale field studies. Fish Shellfish Immunol. 35: 1585-1590.

15. Beck BR, Kim D, Jeon J, Lee SM, Kim HK, Kim OJ, et al. 2015. The effects of combined dietary probiotics Lactococcus lactis BFE920 and Lactobacillus plantarum FGL0001 on innate immunity and disease resistance in olive flounder (Paralichthys olivaceus). Fish Shellfish Immunol. 42: 177-183.

16. Vergara CMDAC, Honorato TL, Maia GA, Rodrigues S. 2010. Prebiotic effect of fermented cashew apple (Anacardium occidentale L) juice. LWT-Food Sci. Technol. 43: 141-145.

17. Cerezuela R, Meseguer J, Esteban MA. 2011. Current knowledge in synbiotic use for fish aquaculture: a review. J. Aquac. Res. Dev. 1: 1-7.

18. Bai SC, Kim KW. 1997. Effects of dietary animal protein sources on growth and body composition in Korean rockfish, Sebastes schlegeli. J. Aqua. 10: 7-85.

19. AOAC 1995. Official Methods of Analysis, 16th ed. Association of Official Analytical Chemists, Arlington, VA, USA.
20. Nikoskelainen S, Ouwehanda AC, Bylundb G, Salminena S, Liliusa EM. 2003. Immune enhancement in rainbow trout (Oncorhynchus mykiss) by potential probiotic bacteria (Lactobacillus rhamnosus). Fish Shellfish Immunol. 15: 443-452.

21. Ellis AE. 1990. Lysozyme Assays, pp. 101-103. In Stolen JS, Fletcher TC, Anderson DP, Roberson, B.S., Van MWB (eds.), Techniques in Fish Immunology, Fair Haven, SOS Publications, Fair Haven.

22. Quade MJ, Roth JA. 1997. A rapid, direct assay to measure degranulation of bovine neutrophil primary granules. Vet. Immunol. Immunop. 58: 239-248.

23. Abid A, Davies SJ, Waines P, Emery M, Castex M, Gioacchini G, et al. 2013. Dietary synbiotic application modulates Atlantic salmon (Salmo salar) intestinal microbial communities and intestinal immunity. Fish Shellfish Immunol. 35: 1948-1956.

24. Van DH, Doolgindachbaporn S, Suksri A. 2014. Effects of low molecular weight agar and Lactobacillus plantarum on growth performance, immunity, and disease resistance of basa fish (Pangasius bocourti, Sauvage 1880). Fish Shellfish Immunol. 41: 340-345.

25. Geraylou Z, Souffreau C, Rurangwa E, Meester LD, Courtin CM, Delcour JA, et al. 2013. Effects of dietary arabinoxylanoligosaccharides (AXOS) and endogenous probiotics on the growth performance, non-specific immunity and gut microbiota of juvenile Siberian sturgeon (Acipenser baerii). Fish Shellfish Immunol. 35: 766-775.

26. Maslowski KM, Mackay CR. 2011. Diet, gut microbiota and immune responses. Nat. Immunol. 12: 5-9.

27. Satyanarayana U, Kumar AN, NaiduJN, Prasad DKV. 2014. Antioxidant supplementation for health-a boon or a bane? J. Dr. NTR Univ. Health Sci. 3: 221-230.

28. Kim YR, Kim EY, Choi SY, Hossain MT, Oh R, Heo WS, et al. 2012. Effect of a probiotic strain, Enterococcus faecium, on the immune responses of olive flounder (Paralichthys olivaceus). J. Microbiol. Biotechnol. 22: 526-529.

29. Reece JB, Urry LA, Cain ML, Wasserman SA, Minorsky PV, Jackson R. 2014. The immune system, pp. 37-47, 9th Ed. Published by Benjamin Cummings, Pearson, Boston, USA.

30. Geng X, Dong XH, Tan BP, Yang QH, Chi SY, Liu HY, et al. 2011. Effects of dietary chitosan and Bacillus subtilis on the growth performance, non-specific immunity and disease resistance of cobia, Rachycentron canadum. Fish Shellfish Immunol. 31: 400-406.

31. Hoseinifar SH, Mirvaghefi A, Amoozegar MA, Sharifian M, Esteban MA. 2015. Modulation of innate immune response, mucosal parameters and disease resistance in rainbow trout (Oncorhynchus mykiss) upon synbiotic feeding. Fish Shellfish Immunol. 45: 27-32.

32. Ai Q, Xu H, Mai K, Xu W, Wang J, Zhang W. 2011. Effects of dietary supplementation of Bacillus subtilis and fructooligosaccharide on growth performance, survival, nonspecific immune response and disease resistance of juvenile 
large yellow croaker, Larimichthys crocea. Aquaculture 317: 155-161.

33. Standen BT, Rawling MD, Davies SJ, Castex M, Foey A, Gioacchini G, et al. 2013. Probiotic Pediococcusacidilactici modulates both localised intestinal-and peripheral-immunity in tilapia (Oreochromis niloticus). Fish Shellfish Immunol. 35: 1097-1104.

34. Kim H, Jung BJ, Jung JH, Kim JY, Chung SK, Chung DK. 2012. Lactobacillus plantarum lipoteichoic acid alleviates TNF$\alpha$-induced inflammation in the HT-29 intestinal epithelial cell line. Mol. Cells 33: 479-486.

35. Dziarski R. 1991. Demonstration of peptidoglycan-binding sites on lymphocytes and macrophages by photoaffinity cross-linking. J. Biol. Chem. 266: 4713-4718.

36. Li W, Pan X, Cheng W, Cheng Y, Yin Y, Chen J, et al. 2018. Serum biochemistry, histology and transcriptome profile analysis reflects liver inflammation and damage following dietary histamine supplementation in yellow catfish (Pelteobagrus fulvidraco). Fish Shellfish Immunol. 77: 83-90.

37. Lieschke GH, Trede NS. 2009. Fish immunology. Curr. Biol. 19: 678-682.

38. Marin ML, Lee JH, Murtha J, Ustunol Z, Pestka JJ. 1997. Differential cytokine production in clonal macrophage and T-cell lines cultured with bifidobacteria. J. Dairy Sci. 80: 2713-2720.

39. Guzmán-Villanueva LT, Tovar-Ramírez D, Gisbert E,
Cordero H, Guardiola FA, Cuesta A, et al. 2014. Dietary administration of $\beta-1,3 / 1,6$-glucan and probiotic strain Shewanella putrefaciens, single or combined, on gilthead seabream growth, immune responses and gene expression. Fish Shellfish Immunol. 39: 34-41.

40. Zhou QC, Buentello JA, Gatlin DM. 2010. Effects of dietary prebiotics on growth performance, immune response and intestinal morphology of red drum (Sciaenops ocellatus). Aquaculture 309: 253-257.

41. Scheller J, Chalaris A, Schmidt-Arras D, Rose-John S. 2011. The pro-and anti-inflammatory properties of the cytokine interleukin-6. BBA- Mol. Cell Res. 1813: 878-888.

42. Dawood MAO, Koshio S, Ishikawa M, Yokoyama S, ElBasuini MF, Hossain MS, et al. 2016. Effects of dietary supplementation of Lactobacillus rhamnosus or/and Lactococcus lactis on the growth, gut microbiota and immune responses of red sea bream, Pagrus major. Fish Shellfish Immunol. 49: 275-285.

43. Mehrabi Z, Firouzbakhsh F, Jafarpour A. 2012. Effects of dietary supplementation of synbiotic on growth performance, serum biochemical parameters and carcass composition in rainbow trout (Oncorhynchus mykiss) fingerlings. J. Anim. Physiol. An. N. 96: 474-481.

44. Ringo E. 2008. The ability of carnobacteria isolated from fish intestine to inhibit growth of fish pathogenic bacteria: a screening study. Aquac. Res. 39: 171-180. 